\title{
A Hierarchical (Multicomponent) Model of In-Group Identification: Examining in Russian Samples
}

\author{
Andrey V. Lovakov, Elena R. Agadullina, Evgeny N. Osin \\ National Research University Higher School of Economics (Russia)
}

This is the author's version of an published article. It may be cited as follows:

Lovakov, A. V, Agadullina, E. R., \& Osin, E. N. (2015). A Hierarchical (Multicomponent)

Model of In-Group Identification: Examining in Russian Samples. Spanish Journal of

Psychology, 18(e32), 1-12. doi:10.1017/sjp.2015.37

This research was supported by the Russian Foundation for Humanities, grant 13-0600519, to Elena Agadullina. We would like to express our appreciation to Olga Gulevich, Milana Hachaturova, Anatoly Skvortsov, and Yuliya Briseva for help in collecting data.

Correspondence concerning this article should be addressed to Andrey Lovakov. Department of Psychology. National Research University Higher School of Economics, 20. Myasnitskaya Ulitsa. Moscow (Russia).101000. E-mail lovakov@hse.ru 


\begin{abstract}
The aim of this study was to examine the validity and reliability of the Leach et al. (2008) model of in-group identification in two studies using Russian samples (overall $N=621$ ). In Study 1, a series of multi-group confirmatory factor analysis revealed that the hierarchical model of ingroup identification, which included two second-order factors, self-definition (individual selfstereotyping, and in-group homogeneity) and self-investment (satisfaction, solidarity, and centrality), fitted the data well for all four group identities (ethnic, religious, university, and gender $)(\mathrm{CFI}>.93, \mathrm{TLI}>.92, \mathrm{RMSEA}<.06, \mathrm{SRMR}<.06)$ and demonstrated better fit, compare to the alternative models. In Study 2, we examined the construct validity and reliability of the Russian version of the in-group identification measure. Results show that these measure have adequate psychometric properties. In short, our results show that the Leach et al. model is reproduced in Russian culture. The Russian version of this measure can be recommended for use in future in-group research in Russian-language samples.
\end{abstract}

Keywords: identity, in-group identification, social identity, group, self-stereotyping 
Research into in-group identification has expanded in recent decades, with the recognition that group membership is a major influence on individual experience and behavior. According to social identity theory (Tajfel, 1978; Tajfel, \& Turner, 1986) and self-categorization theory (Turner, Hogg, Oakes, Reicher, \& Wetherell, 1987) identification with in-groups is an important part of individual self-concept that influences the attitudes and behavior of individuals. Awareness of one's membership in a social group leads one to think and to behave in the ways members of this group do.

There are many conceptualizations and much operationalization of in-group identification in the literature. Some authors operationalize it as a unitary scale, others approach it as a multidimensional construct, but there is little agreement regarding the set of its components (for reviews see Ashmore, Deaux, \& McLaughlin-Volpe, 2004; Leach et al., 2008). Leach et al. (2008) have reviewed different approaches to the conceptualization of in-group identification and systematized its components proposed by different authors in a single logical and coherent model. Their model includes five main components: individual self-stereotyping, in-group homogeneity, solidarity, satisfaction, and centrality. Individual self-stereotyping is the degree to which an individual perceives herself or himself as similar to an in-group prototype. In-group homogeneity is the degree to which an individual perceives her or his in-group as relatively homogeneous and distinct from relevant out-groups. Solidarity refers to a sense of belonging, a psychological attachment to the in-group, and coordination with the other group members. Satisfaction refers to the positive evaluation of the in-group. Centrality is the salience and importance of in-group membership.

Based on this analysis, Leach et al. (2008) developed a hierarchical model of in-group identification, which consists of these five components integrated into two more abstract, higherorder dimensions: self-definition and self-investment (see Figure 1). Leach et al. (2008) operationalized this hierarchical model in a 14-item measure. Most of the items were close adaptations of those used in previous narrow approaches. The authors validated their measure in 
seven studies using different groups (University, Dutch, and European). Results showed that their theoretical first- and second-order factor models fit the data well and the scale was shown to have high internal consistency, concurrent validity, construct validity, and discriminant validity. An independent examination of scale structure conducted by Howard and Magee (2013) showed that the theoretical model has an acceptable fit to the data from different types of ingroups: country, state, university, and online group (the Reddit.com community). This hierarchical model of in-group identification is important because it was created by combining multiple approaches, the main classic and contemporary models of the in-group identification, and specifies similarities and differences between its components. The measure based on this model can be used for studying identification with groups of any type.

The model has been widely used in psychological research. In recent years, the Leach et al. (2008) measure of in-group identification was used in at least 20 studies using different types of target groups: ethnic, national, and racial in-groups (Danel et al., 2012; Giamo, Schmitt, \& Outten, 2012; Koval, Laham, Haslam, Bastian, \& Whelan, 2012; Leach, Mosquera, Vliek, \& Hirt, 2010; Philpot \& Hornsey, 2011; Shepherd, Spears, \& Manstead, 2013; Stürmer et al., 2013; Wang, Minervino, \& Cheryan, 2013), gender in-groups (Correia et al., 2012; Good, MossRacusin, \& Sanchez, 2012; Kenny \& Garcia, 2012), student in-groups (Becker, 2012; Correia et al., 2012; Cruwys et al., 2012; Leach et al., 2010), online in-groups (people from an online forum sharing the same interests) (Howard, 2014; Howard \& Magee, 2013), the army (Sani, Herrera, Wakefield, Boroch, \& Gulyas, 2012), group of experiment participants (Hartmann \& Tanis, 2013; van Veelen, Otten, \& Hansen, 2013), supporters of mental health advocacy (Gee \& McGarty, 2013), and organizational in-group (Smith, Amiot, Callan, Terry, \& Smith, 2012). But, with the exception of two studies (Correia et al., 2012; Danel et al., 2012), the Leach et al. (2008) measure was used only in English-language samples. Danel et al. (2012) and Correia et al. (2012) translated the Leach et al. (2008) items into Polish and Portuguese languages, 
respectively, but did not examine structural validity of their translations. At present time, the measure exists only in the English version.

Group identification is a very popular research topic around the world, including Russian-speaking countries. The Leach et al. (2008) model and measure of in-group identification would be very useful in countries where the issues of ethnic, national, and other types of social identification have not been sufficiently studied. The aim of this study was to examine the Leach et al. (2008) model of in-group identification in three different Russian samples. In Study 1, we focused on the validity of the hierarchical model. We applied confirmatory factor analysis (CFA) to the data from four different in-groups (ethnic, religious, university, and gender). In Study 2, we examined the convergent and discriminant validity of the five components of in-group identification by assessing the component correlations with different measures of in-group identification.

\section{Study 1: Factorial Validity and Reliability Evidences}

\section{Method}

\section{Participants}

Three samples were employed. The first sample included 226 undergraduate students of the Higher School of Economics (86 male, 135 female, 5 respondents did not specify their gender, $M($ age $)=18.13, S D=1.18(5$ people did not specify their age $)$ ). For students, participation in the survey was part of a Psychology course. They completed a paper-and-pencil questionnaire. The second sample included 146 people who identified themselves as Russian (58 male, 88 female, $M($ age $)=33.1, S D=11.8)$. The third sample included 249 people who identified themselves as Orthodox Christian (143 male, 106 female, $M$ (age) = 30, SD=8.6). In the second and third samples, participants completed an online questionnaire. Links to the survey were placed on specialized websites dedicated to psychology and the Russian culture. 


\section{Procedure and measures}

All participants completed a structured questionnaire that included a 14-item measure based on a hierarchical model of in-group identification (Leach et al., 2008). The items were translated from English into Russian by the authors and then back-translated by a bilingual, native speaker of both languages, who was unaware of the subject of the questionnaire. Differences in translations were discussed until agreement was reached. The Russian version of the items can be found in the Appendix. Each item was scored on a 7-point scale, all 7 options verbalized ranging from 1 (absolutely disagree) to 7 (absolutely agree). We created four versions of the measure for each in-group: Russian, Orthodox Christian, gender, and students of the Higher School of Economics. Participants from the student sample completed two 14-item measures: one about the in-group of students of the Higher School of Economics, and one about the gender in-group. Before the start of the survey the respondents were informed about the purpose and procedure of the study, as well as their right to withdraw from the study at any time. In all samples the survey was anonymous and the respondents were informed that their answers would be kept confidential and used only for research purposes.

\section{Results}

We performed CFAs with Mplus 6.12 (estimator - MLMV) to examine how well the proposed measurement model fitted the Russian version of the 14-item measure of in-group identification. We estimated the proposed measurement model separately for four types of ingroups: Russians, Orthodox, university, and gender. First we examined the first-order model, which consists of five components: individual self-stereotyping, in-group homogeneity, solidarity, satisfaction and centrality (Model A). The results (shown in Table 1) indicate that Model A fitted the data well for all four group identities. The fit indices (excluding TLI in the case of the gender in-group) exceeded the benchmark of .930 and both of the main residual indices fell below the benchmark of .080 for models of this sample size (see Hu \& Bentler, 
1999). In all four in-groups, Model A showed the best fit to the data. Following Leach et al.

(2008), we compared Model A with three alternative first-order measurement models (Model B $=$ all items loading on one common factor: identification; Model $\mathrm{C}=$ items loading on two components: self-definition and self-investment; Model D = items loading on two components: cognitive/self-categorization and affective ties/social identity). The fit of all three alternative models was worse. Because the alternative models were based on the same data, but not nested, they can be compared using the Akaike information criterion (AIC) index (Byrne, 2011). As shown in Table 1, Model A has the lowest AIC in all four samples, which suggests that Model A is the best first-order model.

Table 1.

The Fit of Models of In-Group Identification

\begin{tabular}{llllllll}
$\begin{array}{l}\text { Measurement } \\
\text { model }\end{array}$ & $\chi^{2}, p$ & $d f$ & RMSEA [90\% CI] & CFI & TLI & SRMR & AIC \\
\hline
\end{tabular}

\section{Russians}

Stage 1: first-order models

\begin{tabular}{llllllll} 
Model A & $90.56, p=.029$ & 67 & $.049[.017, .073]$ & .970 & .959 & .049 & 5801.92 \\
Model B & $231.70, p<.001$ & 77 & $.117[.100, .135]$ & .804 & .768 & .082 & 6119.58 \\
Model C & $177.78, p<.001$ & 76 & $.096[.078, .114]$ & .871 & .845 & .073 & 5991.71 \\
Model D & $172.81, p<.001$ & 76 & $.093[.075, .112]$ & .877 & .853 & .064 & 5981.07 \\
Stage 2: second-order models & & & & & & \\
Model E & $98.59, p=.017$ & 71 & $.052[.023, .075]$ & .965 & .955 & .059 & 5807.45 \\
Model F & $106.05, p=.006$ & 72 & $.057[.032, .079]$ & .957 & .945 & .063 & 5821.58 \\
Model G & $98.60, p=.017$ & 71 & $.052[.023, .075]$ & .965 & .955 & .054 & 5808.22 \\
\hline
\end{tabular}

\section{Orthodox (Christians)}

Stage 1: first-order models

\begin{tabular}{llllllll} 
Model A & $98.09, p=.008$ & 67 & $.043[.023, .061]$ & .949 & .931 & .046 & 8540.13 \\
Model B & $243.77, p<.001$ & 77 & $.093[.080, .107]$ & .729 & .679 & .077 & 8824.51 \\
Model C & $171.98, p<.001$ & 76 & $.071[.057, .085]$ & .844 & .813 & .067 & 8673.51 \\
Model D & $219.98, p<.001$ & 76 & $.087[.074, .101]$ & .766 & .720 & .080 & 8764.16 \\
Stage 2: second-order models & & & & & & \\
Model E & $102.29, p=.009$ & 71 & $.042[.022, .059]$ & .949 & .935 & .047 & 8537.77 \\
Model F & $111.15, p=.002$ & 72 & $.047[.028, .063]$ & .936 & .920 & .053 & 8552.55 \\
Model G & $111.10, p=.002$ & 71 & $.048[.030, .064]$ & .935 & .916 & .053 & 8553.94 \\
\hline
\end{tabular}

\section{Students}

Stage 1: first-order models

Model A

Model B

Model C

Model D

Stage 2:

Model E

Model F

Model G

$113.00, p<.001$
$381.90, p<.001$
$236.04, p<.001$
$266.14, p<.001$
der models
$122.84, p<.001$
$144.60, p<.001$
$128.20, p<.001$

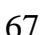

77

76

76

71

72

71

$.056[.038, .074]$
$.135[.122, .149]$
$.099[.085, .113]$
$.108[.094, .122]$
$.058[.040, .075]$
$.068[.052, .084]$
$.061[.044, .078]$

$\begin{array}{llll}.953 & .937 & .049 & 8456.26 \\ .690 & .634 & .105 & 8960.96 \\ .837 & .805 & .082 & 8677.28 \\ .807 & .769 & .109 & 8737.59 \\ & & & \\ .947 & .932 & .058 & 8464.27 \\ .926 & .907 & .072 & 8506.83 \\ .942 & .926 & .065 & 8477.54\end{array}$


Males / Females

Stage 1: first-order models

Model A

127.91, $p<.001$

$67 \quad .065[.048, .082]$

$.152[.138, .165]$

.933

$.909 \quad .058$

8986.81

Model B

456.03, $p<.001$

$.112[.098, .126]$

.581

$.505 \quad .123$

9552.81

Model C

$280.12, p<.001$

$.121[.107, .135]$

.774

$.730 \quad .095$

9234.68

Model D

$312.26, p<.001$

76

.739

$.687 \quad .127$

9284.53

Stage 2: second-order models

Model E

129.56, $p<.001$

Model F

$158.40, p<.001$

$.062[.045, .079]$

.935

$.917 \quad .059$

8980.78

Model G $147.52, p<.001$

$.075[.059, .091]$

.905

$.879 \quad .077$

9029.23

$71 \quad .071[.055, .087]$

$.915 \quad .892 \quad .082$

9011.92

Note. $d f$ = degrees of freedom; RMSEA - root-mean-square error of approximation; CFI - comparative fit index;

TLI - Tucker-Lewis index; SRMR - standardized root-mean square residual; AIC - Akaike information criterion.

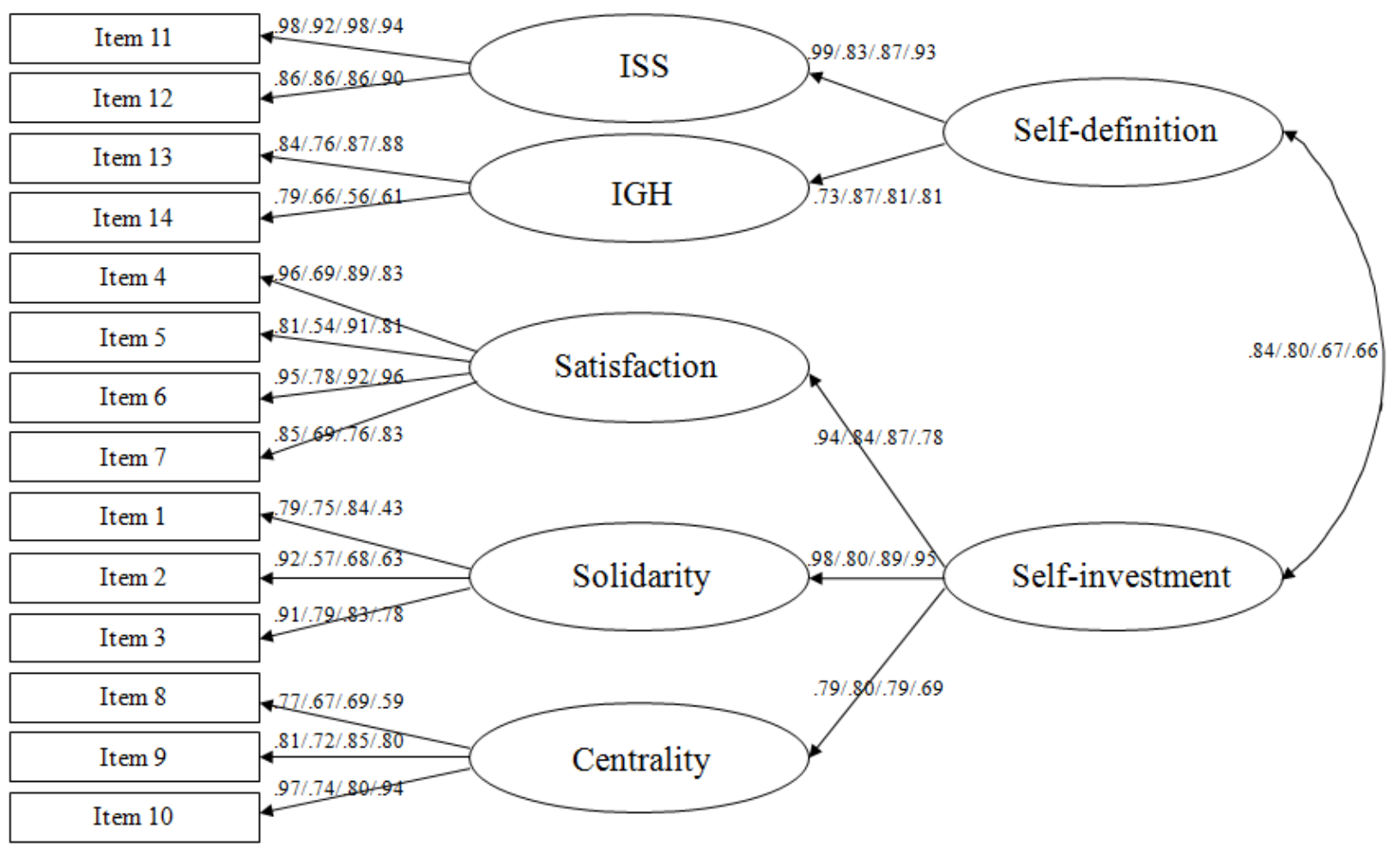

Figure 1. Hierarchical (multicomponent) model of in-group identification. Standardized item loadings are presented in the following order: Russians/Orthodox (Christians)/Students/Males \& Females. ISS - individual self-stereotyping; IGH - in-group homogeneity.

Second, we examined the hierarchical model (Model E), which included the second-order factors of self-definition (i.e., individual self-stereotyping and in-group homogeneity) and selfinvestment (i.e., satisfaction, solidarity, centrality). This model is shown on Figure 1. Model E fitted the data well for all four group identities (Table 1). The fit indices (excluding TLI in the case of the gender in-group) exceeded the benchmark of .930 , and both of the main residual 
indices fell below the benchmark of .080. In all four samples Model E had the lowest AIC, which means Model E is the best second-order model.

As Figure 1 shows, the standardized factor loadings exceeded .50 for nearly all items (excluding the first item in the gender in-group), with many above .80, and differed significantly from zero $(p<.05)$. Each of the five components loaded onto the expected second-order factor. All the second-order factor loadings exceeded .60, with many above .80, and differed significantly from zero $(p<.05)$. The second-order factors of self-definition and self-investment were strongly and significantly related in all samples (.66-.84, all $p<.05)$. All of these parameters confirm that Model E, with five components and two second-order factors, was well defined by its items. The fit indices indicate that Model E fitted the data better, compared to the two alternative models (Model F = five-components: individual self-stereotyping, in-group homogeneity, solidarity, satisfaction and centrality, and one dimension: identification; Model G = alternative five-component/two-dimensional: self-definition (i.e., individual self-stereotyping, in-group homogeneity, and centrality) and self-investment (i.e., satisfaction, solidarity).

In order to investigate the factorial invariance of the instrument, we performed a series of multi-group CFA analyses testing configural, metric, and scalar invariance of the model across the 4 samples. Latent factors were identified by fixing variance to 1 . Because the complete firstand second-order configural invariance model had convergence issues, we started by establishing the invariance of the first-order structure and then used the scalar-invariant first-order model as a baseline for the second-order models. This strategy resulted in a sequence of nested models, allowing to use the DIFFTEST function in order to compare the fit. As the chi-square test is overly sensitive in large samples, we relied on the $\Delta \mathrm{CFI}>.01$ criterion of a significant difference between nested models (Cheung \& Rensvold, 2002). At each stage, we first evaluated the fit of a completely invariant model and then proceeded by establishing partial measurement invariance (Byrne, 2011; Byrne, Shavelson, \& Muthen, 1989). The results of model fit tests are summarized in Table 2 and those of model comparison are presented in Table 3. 
Table 2.

The Fit of Multi-Group Models of In-Group Identification

\begin{tabular}{|c|c|c|c|c|c|c|}
\hline Model & $\chi^{2}, p$ & $d f$ & RMSEA [90\% CI] & CFI & TLI & SRMR \\
\hline \multicolumn{7}{|c|}{ Full measurement invariance approach } \\
\hline \multicolumn{7}{|c|}{ Stage 1: first-order models } \\
\hline Model 1 (configural) & $422.27, p<.001$ & 268 & $.053[.043, .062]$ & .953 & .936 & .051 \\
\hline Model 2a (metric) & $485.89, p<.001$ & 295 & $.056[.047, .065]$ & .941 & .928 & .077 \\
\hline Model 3a (scalar) & $693.58, p<.001$ & 322 & $.075[.067, .082]$ & .886 & .871 & .099 \\
\hline \multicolumn{7}{|c|}{ Stage 2: second-order models } \\
\hline Model 4a (configural) & $716.81, p<.001$ & 338 & $.074[.066, .081]$ & .884 & .875 & .102 \\
\hline Model 5a (metric) & $728.54, p<.001$ & 347 & $.073[.066, .080]$ & .883 & .877 & .106 \\
\hline Model 6a (scalar) & $777.90, p<.001$ & 353 & $.076[.069, .084]$ & .869 & .865 & .118 \\
\hline Model 7a (factor cov) & $806.97, p<.001$ & 356 & $.078[.071, .086]$ & .861 & .858 & 188 \\
\hline \multicolumn{7}{|c|}{ Partial measurement invariance approach } \\
\hline \multicolumn{7}{|c|}{ Stage 1: first-order models } \\
\hline Model 2b (metric) & $471.59, p<.001$ & 294 & $.054[.045, .063]$ & .945 & .932 & .073 \\
\hline Model 3b (scalar) & $532.00, p<.001$ & 317 & $.057[.049, .066]$ & .934 & .924 & .079 \\
\hline \multicolumn{7}{|c|}{ Stage 2: second-order models } \\
\hline Model $4 \mathrm{~b}$ (configural) & $556.37, p<.001$ & 333 & $.057[.049, .065]$ & .931 & .925 & .082 \\
\hline Model 5b (metric) & $570.11, p<.001$ & 342 & $.057[.049, .065]$ & .930 & 925 & .088 \\
\hline Model 6b (scalar) & $575.86, p<.001$ & 346 & $.057[.048, .065]$ & .929 & .926 & .088 \\
\hline Model $7 \mathrm{~b}$ (factor cov) & $575.45, p<.001$ & 347 & $.056[.048, .065]$ & .930 & .926 & .088 \\
\hline
\end{tabular}

Note. $d f=$ degrees of freedom; RMSEA - root-mean-square error of approximation; CFI comparative fit index; TLI - Tucker-Lewis index; SRMR - standardized root-mean square residual.

Table 3.

Multi-group model comparison results

\begin{tabular}{lllll}
\hline Model comparison & \multicolumn{1}{c}{$\boldsymbol{\Delta} \boldsymbol{\chi}^{2}, \boldsymbol{p}$} & $\boldsymbol{\Delta d f}$ & $\boldsymbol{\Delta R M S E A}$ & $\boldsymbol{\Delta C F I}$ \\
\hline Full measurement invariance & & & \\
Model 2a vs. Model 1 & $83.28, p<.001$ & 27 & .003 & .012 \\
Model 3a vs. Model 2a & $381.81, p<.001$ & 27 & .019 & .055 \\
Model 4a vs. Model 3a & $31.28, p=.012$ & 16 & .001 & .002 \\
Model 5a vs. Model 4a & $16.10, p=.065$ & 9 & .001 & .001 \\
Model 6a vs. Model 5a & $88.21, p<.001$ & 6 & .003 & .014 \\
Model 7a vs. Model 6a & $30.09, p<.001$ & 3 & .002 & .008 \\
Partial measurement invariance & & & \\
Model 2b vs. Model 1 & $65.36, p<.001$ & 26 & .001 & .008 \\
Model 3b vs. Model 2b & $96.35, p<.001$ & 23 & .003 & .009 \\
Model 4b vs. Model 3b & $31.40, p=.012$ & 16 & $<.001$ & .003 \\
Model 5b vs. Model 4b & $17.78, p=.038$ & 9 & $<.001$ & .001 \\
Model 6b vs. Model 5b & $7.96, p=.093$ & 4 & $<.001$ & .001 \\
Model 7b vs. Model 6b & $0.00, p=.987$ & 1 & .001 & $<.001$ \\
\hline
\end{tabular}

Note. $\Delta d f=$ difference in degrees of freedom; $\triangle \mathrm{RMSEA}$ - change in root-mean-square error of approximation; $\triangle \mathrm{CFI}$ - change in comparative fit index.

The fit of the first-order configural invariance model (1) was good. Though the fit of the full metric invariance model (2a) was statistically worse, the absolute difference was not large and there were no pronounced outliers among modification indices $(\mathrm{MI})$. The strongest $\mathrm{MI}\left(\chi^{2}=\right.$ 12.26) referred to the loading of item 2 in the Orthodox sample; removal of the respective constraint resulted in a statistically significant, but marginal improvement of the model (2b). The 
fit of the first-order full scalar invariance model (3a) was much worse, compared to the model 2a, suggesting some strongly non-equivalent item intercepts. Based on MI, we relaxed intercept constraints (one at a time) for item 3 in the Gender sample $\left(\chi^{2}=44.94\right)$, item 2 in the Student sample $\left(\chi^{2}=38.55\right)$, item 5 in the Orthodox sample $\left(\chi^{2}=26.34\right)$, and item 8 in the Student sample $\left(\chi^{2}=22.54\right)$. The resulting partial scalar invariance model $(3 \mathrm{~b}$, based on model $2 \mathrm{~b})$ had no pronounced MIs for intercepts (the strongest MI: $\chi^{2}=6.70$ ) and exhibited satisfactory fit.

When configural invariance second-order part of the model was introduced into the models $3 \mathrm{a}$ and $3 \mathrm{~b}$, the fit did not become worse, according to the $\triangle \mathrm{CFI}$ criterion, both for the model developed using full invariance approach (4a) and partial invariance approach (4b). Introduction of metric invariance constraints into the second-order part of the model did not lead to a deterioration of model fit either (models $5 \mathrm{a}$ and $5 \mathrm{~b}$ ). There was empirical underidentification in the means part of the second-order scalar invariance model, and second-order factor means for Student and Gender samples were constrained to 0 in order for the models $6 \mathrm{a}$ and $6 \mathrm{~b}$ to converge. Comparison of model fit indices indicated some pronounced non-invariance of factor intercepts, and we relaxed constraints for the intercepts of second-order solidarity factor in the Gender sample $\left(\chi^{2}=54.03\right)$ and the individual self-stereotyping factor in the Orthodox sample $\left(\chi^{2}=21.70\right)$, after which the fit of model $6 \mathrm{~b}$ did not differ statistically from that of model $5 b$.

Finally, in model 7 we constrained the covariance of second-order factors to be equal across groups. Because the model fit deteriorated, in the partially invariant model we relaxed this constraint for the Russian sample $\left(\chi^{2}=28.04\right)$ and for the Orthodox sample $\left(\chi^{2}=10.09\right)$, after which the fit indices of the models $6 \mathrm{~b}$ and $7 \mathrm{~b}$ did not differ.

Finally, we computed the scale scores for each component. All the five scales were of moderate or high reliability, Cronbach's $\alpha$ ranged between .65 and .93 (see Table 4). Correlations between the five components were moderate or high, but in all four in-groups intercorrelations were higher for the components referring to the same dimension. Satisfaction, 
solidarity, and centrality have higher correlations with each other than with individual self-

stereotyping or with in-group homogeneity, but correlations between individual self-stereotyping and in-group homogeneity were higher than their correlations with satisfaction, solidarity, and centrality (see Table 4). This supports the hierarchical conceptualization proposed by Leach et al. (2008) and the results of the CFA. Therefore, the results support the use of the subscales and confirm the structural validity of the Russian version of the measure.

Table 4.

Descriptive Statistics and Inter-correlations for Five Components of In-Group Identification

\begin{tabular}{lllllllll}
\hline In-group / Component & $\boldsymbol{M}$ & $\boldsymbol{S D}$ & $\boldsymbol{\alpha}$ & $\mathbf{1}$ & $\mathbf{2}$ & $\mathbf{3}$ & $\mathbf{4}$ & $\mathbf{5}$ \\
\hline Russians & & & & & & & & \\
1. Individual self-stereotyping & 5.20 & 1.58 & .91 & - & & & \\
2. In-group homogeneity & 5.00 & 1.39 & .77 & $\mathbf{. 6 7 ^ { * * }}$ & - & & \\
3. Satisfaction & 5.87 & 1.34 & .93 & $.66^{* *}$ & $.52^{* *}$ & - & \\
4. Solidarity & 5.68 & 1.38 & .90 & $.69^{* *}$ & $.55^{* *}$ & $\mathbf{. 7 9 * *}$ & - \\
5. Centrality & 5.25 & 1.69 & .89 & $.68^{* *}$ & $.60^{* *}$ & $\mathbf{. 7 4}$ & $\mathbf{. 7 2}$ & - \\
\hline
\end{tabular}

Orthodox (Christians)

1. Individual self-stereotyping

$3.43 \quad .89 \quad .88$

2. In-group homogeneity

$2.97 \quad .91$

3. Satisfaction

$4.44 \quad .68$

4. Solidarity

$4.33 \quad .80$

5. Centrality

3.92

.94

.88
.67
.73
.73
.74

\begin{tabular}{|c|c|}
\hline $.56^{* *}$ & - \\
\hline $46^{* *}$ & $.38^{* *}$ \\
\hline $.44^{* *}$ & $.44^{* *}$ \\
\hline $.42^{* *}$ & $.39^{* *}$ \\
\hline
\end{tabular}
$.51^{* *}$ $.44^{* *}$

\section{Students}

1. Individual self-stereotyping

$\begin{array}{lll}4.40 & 1.31 \quad .90\end{array}$

2. In-group homogeneity

4.03

3. Satisfaction

5.89

4. Solidarity

5.27

1.18

.65

$1.12 \quad .92$

5. Centrality

$1.13 \quad .83$

$1.33 \quad .82$

$-50^{* *}$
$.41^{*}$
$.42^{*}$
.44

$-$

$41^{* *} .31^{* *}$

$.42^{* *} \quad .30^{* *}$

$.44^{* *}$

$.40^{* *}$

$.67^{* * *}$ $.50 *$

\section{Males / Females}

1. Individual self-stereotyping

2. In-group homogeneity

4.46

3. Satisfaction

4.24

4. Solidarity
5. Centrality

5.84

1.46

1.39

1.20

.91

.69

$-$

$\begin{array}{ll}1.08 & .70\end{array}$

$.59^{* *}$

$.39^{* *}$

$1.27 \quad .81$

$.36^{* *}$

24

$.47^{* * *}$

$.23^{* *} \quad .47^{* *} \quad .37^{* * *}$

Note. In the Orthodox sample we used a 5-point scale. Therefore, means and standard deviations are lower than in the student and Russian samples. Bold correlations are those of scales that refer to the same dimension. $* * p<.01$

\section{Study 2: Examining Validity}

We performed additional studies to examine the convergent and discriminant validity of the Russian version of the measure of in-group identification. As part of the same survey session, 
two of the three Study 1 samples (undergraduate students of the Higher School of Economics and people who identified themselves as Russians) completed several additional measures related to the in-group identification.

\section{Method}

\section{Participants and Measures}

\section{Sample 1}

146 people who identified themselves as Russians in Study 1 completed several additional measures.

\section{Multigroup Ethnic Identity Measure (MEIM)}

To gauge the convergent validity of the Leach et al. (2008) measure, we used MEIM (Phinney, 1992). This scale consists of 12 items scored on a 4-point frequency scale and comprises two subscales: Affirmation and Belonging $(\alpha=.92)$, and Identity Search $(\alpha=.84)$. Participants completed the Russian version of the MEIM (sample items: "I am glad that I belong to Russians", "I follow the traditions of Russians") (Tatarko \& Lebedeva, 2011). Participants were asked to indicate their identification as Russians (as opposed to immigrants from Central Asian countries). As Leach et al. (2008) suggested, the Affirmation and Belonging subscale includes items similar to the solidarity, centrality, and satisfaction components and the Identity Search subscale includes items similar to the centrality and satisfaction components.

\section{Self-Group Overlap}

This graphical scale was used to assess the self-inclusion of respondents in their in-group (Schubert \& Otten, 2002). Seven pictures, with two circles on each, showed different degrees of overlap. The first circle represented the respondent, the second circle represented the in-group (Russians). Participants were asked to choose the pair of circles that best describes the overlap between him/her and the in-group. The choice was translated into a 7-point scale with higher scores indicating higher overlap. Swann, Gomez, Seyle, Morales, and Huici (2009) showed that 
group identification is associated with fusion, defined as "a powerful union of the personal and social self wherein the borders between the two become porous without diminishing the integrity of either construct" (Swann, Jetten, Gomez, Whitehouse, \& Bastian, 2012, p. 443). It means that a highly identifying person fuses with a group. As Leach et al. (2008) suggested, the inclusion of the self in the in-group should be associated especially with individual self-stereotyping.

\section{Positivity of Ethnic Identity Scale}

This scale consists of 4 items scored on a 5-point scale (sample item: "If I have the opportunity to choose an ethnic group, I would choose the same"), which ranged from 1 (absolutely disagree) to 5 (strongly agree). Positivity of ethnic identity refers to positive emotions based on ethnic group membership (Tatarko \& Lebedeva, 2011). We expected the Positivity of ethnic identity subscale $(\alpha=.61)$ to be associated with satisfaction and solidarity components.

\section{Sample 2}

226 undergraduate students of the Higher School of Economics from Study 1 completed several additional measures.

\section{Group Entitativity Measure (GEM-in)}

GEM-in (Gaertner \& Schopler, 1998) is a modification of the Inclusion of Other in the Self scale (Aron, Aron, \& Smollan, 1992) and is composed of six diagrams. On each diagram there are five similar circles representing in-group members. On the first diagram the circles are far apart; on the last diagram they overlap. Gaertner and Schopler (1998) suggest that GEM-in is sensitive to changes in both intragroup similarity and interdependence. We expected perceived group entitativity to be associated with in-group homogeneity and solidarity.

\section{Brief Scale of In-Group Emotions}

Emotions associated with in-group membership were measured by adapting a version of Brief Scale of Ethnical Membership Emotions (Tatarko \& Lebedeva, 2011). We changed the focus of this single-item scale from ethnic membership to university and gender group 
membership: "What do you feel about the fact of belonging to the Higher School of Economics/male or female group?" Participants had to choose one of the 5 responses: 1 humiliation, 2-offense embarrassment, 3 - no feelings, 4 - quiet confidence, 5 - pride. We expected that in-group emotions would be associated most strongly with the satisfaction component.

\section{Self-Group Overlap}

The same measure as used in Sample 1; the first circle represented the participant, the second circle represented the in-group (in the first case, students of the Higher School of Economics, in the second case, the male or female group).

\section{Intention to leave}

The Intention to leave in-group was assessed only for the university in-group and was measured by 2 items (Spearman-Brown Coefficient $=.84$ ): "If I had the opportunity to study at another university, I would have done it" and "I often think that my choice of university was wrong, and it would be nice to study at another university". Each item was scored on a 7-point frequency scale, which ranged from 1 (absolutely disagree) to 7 (strongly agree). When individuals identify with a group, they are less likely to intend to leave the group (Abrams, Ando, \& Hinkle, 1998; Riketta, 2005). We expect that the intention to leave the in-group should be negatively associated with satisfaction and centrality components.

\section{Results}

Table 5 shows the correlations between the five components of in-group identification and the different measures related to in-group identification. Following Leach et al. (2008), we calculated the partial correlations which control for satisfaction, because satisfaction is the general and strongest component of in-group identification that tends to demonstrate the highest correlations with different scales. 
Table 5.

Correlations of five components of in-group identification with different measures related to the in-group identification used in Study 2

\begin{tabular}{|c|c|c|c|c|c|}
\hline Measure & ISS & IGH & Satisfaction & Solidarity & Centrality \\
\hline \multicolumn{6}{|c|}{ Russians } \\
\hline \multicolumn{6}{|c|}{ Ethnical identity (Identity Search) } \\
\hline$r$ & $.55^{* *}$ & $.54^{* *}$ & $.59^{* *}$ & $.62^{* *}$ & $.71^{* *}$ \\
\hline$p r$ & $.26^{* *}$ & $.33^{* *}$ & - & $.30^{* *}$ & $.46^{* *}$ \\
\hline \multicolumn{6}{|c|}{$\begin{array}{l}\text { Ethnical identity (Affirmation and } \\
\text { Belonging) }\end{array}$} \\
\hline$r$ & $.60^{* *}$ & $.58^{* *}$ & $.72^{* *}$ & $.71^{* *}$ & $.70^{* *}$ \\
\hline$p r$ & $.21^{* *}$ & $.32^{* *}$ & - & $.31^{* *}$ & $.30^{* *}$ \\
\hline \multicolumn{6}{|c|}{ Positivity of identity } \\
\hline$r$ & $.35^{* *}$ & $.27^{* *}$ & $.52^{* *}$ & $.46^{* *}$ & $.38^{* *}$ \\
\hline$p r$ & .05 & -.00 & - & $.18^{*}$ & -.05 \\
\hline \multicolumn{6}{|c|}{ Self-Group Overlap } \\
\hline$r$ & $.46^{* *}$ & $.40^{* *}$ & $.50^{* *}$ & $.44^{* *}$ & $.50^{* *}$ \\
\hline$p r$ & .15 & $.19^{*}$ & - & .10 & $.19^{*}$ \\
\hline
\end{tabular}

\section{Students}

Group Entitativity

$\begin{array}{llllll}r & .31^{* *} & .32^{* *} & .49^{* *} & .41^{* * *} & .28^{* * *} \\ p r & .11 & .23^{* *} & - & .15^{*} & -.01\end{array}$

In-Group Emotions

$\begin{array}{llllll}r & .33^{* *} & .23^{* *} & .60^{* * *} & .42^{* * *} & .55^{* *} \\ p r & .07 & .06 & - & .09 & .27^{* *}\end{array}$

Self-Group Overlap

$\begin{array}{llllll}r & .32^{* *} & .23^{* *} & .40^{* *} & .39^{* * *} & .24^{* *} \\ p r & .22^{* *} & .14^{*} & - & .22^{* *} & .02\end{array}$

Intention to leave

\begin{tabular}{llllll}
$r$ & $-.23^{* *}$ & $-.17^{*}$ & $-.59^{* *}$ & $-.39^{* *}$ & $-.28^{* *}$ \\
$p r$ & .07 & .06 & - & .05 & $-.23^{* *}$ \\
\hline
\end{tabular}

\section{Males / Females}

Group Entitativity

$\begin{array}{clllll}r & .22^{* * *} & .27^{* *} & .19^{* * *} & .29^{* *} & .20^{* *} \\ p r & .17^{* *} & .23^{* *} & - & .20^{* *} & .15^{*} \\ \text { In-Group Emotions } & & & & & \\ r & .32^{* *} & .20^{* *} & .46^{* *} & .28^{* *} & .37^{* *} \\ p r & .12 & .05 & - & -.02 & .11\end{array}$

Self-Group Overlap

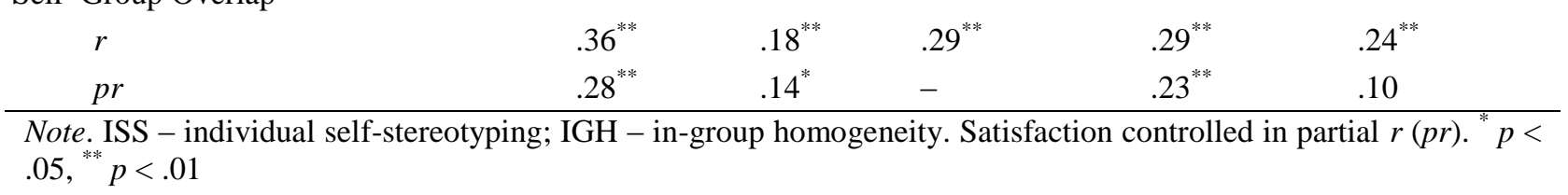

All the components were moderately correlated with the subscales of MEIM (Phinney, 1992). We expected that the Affirmation and Belonging subscale would correlate with the solidarity, centrality, and satisfaction components, and the Identity Search subscale would 
correlate with the centrality and satisfaction components of in-group identification. As shown in Table 3, there were statistically significant correlations between the Affirmation and Belonging subscale and the satisfaction, in-group homogeneity, solidarity, centrality and individual selfstereotyping components. The Identity Search subscale had statistically significant correlations with the satisfaction, centrality, in-group homogeneity, solidarity, and individual selfstereotyping components. These correlations indicate that the constructs measured by Leach's et al. (2008) items and MEIM measure are closely related. At the same time, the moderate effect sizes of the correlations suggest that the five components of in-group identification and Phinney's measures of ethnic identification measure similar but distinct aspects of identification. The pattern of the correlations between Phinney's scales and the components of in-group identification differs from that obtained by Leach et al. (2008), which may results from nonequivalence of the English and Russian versions of the measures.

The satisfaction component had moderate correlations with the Positivity of Identity subscale, positive feelings about the in-group, and intention to leave the in-group. Consistent with the theoretical conceptualization, the satisfaction component refers to a positive evaluation of the in-group and it means that the person who is satisfied with his or her membership has positive feelings about membership and is intending to stay in the group (Stryker \& Serpe, 1982). These correlations suggest a convergent validity of the satisfaction component scale. Moreover, the satisfaction component had also significant correlations with self-group overlap and group entitativity. These weaker correlations are consistent with the satisfaction being a general component of in-group identification, which has the strongest relationship to all the other facets of group identification.

The individual self-stereotyping component was correlated with self-group overlap. Because the self-group overlap in the graphical measure is a visual metaphor for selfcategorization (Schubert \& Otten, 2002), these correlations suggest convergent validity of the self-stereotyping component scale. 
The in-group homogeneity component correlated with perceived group entitativity. Because perceived group entitativity is theoretically close to group homogeneity (Hamilton, Sherman, \& Castelli, 2002; Pickett \& Perrott, 2004), these results suggest the convergent validity of the in-group homogeneity component.

The solidarity component was associated with perceived group entitativity and self-group overlap. Solidarity refers to a sense of belonging, a psychological attachment to the in-group, and coordination with other group members. Lickel et al. (2000) demonstrated that the importance of the group to group members and the interaction among group members are significant parts of the perception of group entitativity. In other words, solidarity is similar to group entitativity. Moreover, self-group overlap as a degree of unity among group members also describes the relationship between group members and attitudes to a group (Schubert \& Otten, 2002). All of these results support the convergent validity of the solidarity component.

The centrality component was correlated with the intention to leave in-group and emotions about in-group. Centrality is the salience and importance of in-group membership. Brewer (1988) argues that group members have two main needs, the desire to preserve their identity and the desire to belong to the group. It means that higher salience and importance of ingroup membership (the centrality component) are associated with lower intention to leave the group.

There were unexpectedly low correlations of self-group overlap with in-group homogeneity and centrality for the Russian group, with solidarity and in-group homogeneity for the university group and solidarity for the gender group. These correlations may reflect differences in the understanding of overlap by participants.

In general, the associations between the five components of in-group identification and other measures followed our theoretical expectations and suggested validity of the five scales. In Study 2, the Russian version of the Leach et al. (2008) measure was shown to have adequate convergent and discriminant validity. 


\section{General Discussion}

The main goal of this study was to examine the Leach et al. (2008) model of in-group identification and to establish convergent and divergent validity of the Russian version of the measure. In order to meet this goal, we conducted two studies using different types of social groups as targets. The results of Studies 1 and 2 have several main consequences.

First, our data showed that the structure of the hierarchical model of in-group identification by Leach et al. (2008) is successfully replicated in the Russian samples. The same first- and second-order factors exist in the Russian sample data and the theoretical second-order factor model is indeed the best-fitting one. We can, therefore, assume that the model may be culturally universal, because it holds for the Dutch sample (Leach et al., 2008), and was successfully replicated in the American (Howard \& Magee, 2013) and now in Russian samples. However, because all these three cultures can be classified as Western cultures, further studies using more diverse cultural contexts are needed to confirm the cultural universality of the model. The results suggest that the measure can be a useful tool for cross-cultural research, once its cross-cultural measurement invariance is established.

Second, the Russian version of the measure of in-group identification has the same factor structure when it is used with different types of in-groups. The results of measurement invariance analyses suggest that the measure exhibits configural and metric invariance across the 4 target in-groups. The only non-equivalent loading parameter for item 2 ("I feel solidarity with...”) suggests that Russian-speaking respondents perceive literal "solidarity" (traditionally, a part of political discourse in the Russian language) as a less relevant expression for solidarity with members of one's religious group, in contrast to groups of other types. However, a number of non-invariant intercepts indicate that some identity items are perceived by respondents differently when they are applied to different target in-groups. For instance, respondents showed a stronger tendency to endorse item 3 for gender identity ("I feel committed to men / women"), which may reflect the ambiguity this item gains in the gender context. Lower intercept of item 2 
for the student group suggests that it is more difficult to "feel solidarity" with a very diverse social group. Lower intercept of item 5 ("I think that ... have a lot to be proud of") for the Orthodox group is explained by the negative evaluation of pride within the religious context. Higher intercept of item 8 ("I often think about the fact that I am...") for the student group can be explained by contextual factors (students completed the questionnaire at the university). Nonequivalence of first-order factor intercepts is in line with the other findings. For instance, "solidarity" and "bond" with members of one's own sex are perceived by the respondents differently from those with members of one's own religion, profession, or country, resulting in a much lower intercept for the respective factor. Because second-order self-definition factor has only two indicators, it is not clear whether intercept non-equivalence for the Orthodox group relates to the individual self-stereotyping or to the in-group homogeneity component. Finally, non-equivalence of factor covariances indicates that self-definition and self-investment components of in-group identity are more strongly related in the cases of ethnic and religious identity, compared to gender and professional contexts. Overall, the results suggest that intercept non-equivalence may bias the analyses that compare raw scores on the in-group identification scales for different target in-groups. Qualitative methods, such as focus groups or cognitive interviewing, may be used to find out the substantive reasons for this bias.

Third, the Russian-language version of the measure was shown to have excellent internal reliability, high internal consistency, satisfactory convergent validity, and divergent validity. Confirmatory factor analysis supported the structural validity of the measure. Overall, we conclude that the Russian version of this measure shows adequate psychometric properties, and it can be used for future in-group research in Russian-language samples.

Our study is not without limitations. The validation of the Russian version of the Leach et al. (2008) measure of in-group identification is not complete. There are a lot of alternative constructs that could have been measured in order to check the validity of the measure. The present study used data from a cross-sectional design. A longitudinal design could be employed 
in future research to investigate test-retest reliability of the measure. The Russian version measure of the in-group identification measure has only been investigated using four types of ingroups. This and previous research investigated in-group identification with groups categorized by Lickel et al. (2000) as "social groups". Usually these are large groups, with a lower degree of similarity, solidarity and interaction between group members (such as race, ethnicity, and gender). In contrast, there are two other types of group: the intimacy group (such a family or two people in a romantic relationship) and task-oriented groups (for instance, committees and work groups). Lickel et al. (2000) demonstrated that identification with different types of groups is varied. This means that the model of in-group identification needs to be validated with intimacy and task-oriented groups. 


\section{References}

Abrams, D., Ando, K., \& Hinkle, S. (1998). Psychological attachment to the group: Crosscultural differences in organizational identification and subjective norms as predictors of workers' turnover intentions. Personality and Social Psychology Bulletin, 24, 1027-1039. http://dx.doi.org/10.1177/01461672982410001

Aron, A., Aron, E. N., \& Smollan, D. (1992). Inclusion of Other in the Self Scale and the structure of interpersonal closeness. Journal of Personality and Social Psychology, 63, 596-612. http://dx.doi.org/10.1037//0022-3514.63.4.596

Ashmore, R. D., Deaux, K., \& McLaughlin-Volpe, T. (2004). An organizing framework for collective identity: Articulation and significance of multidimensionality. Psychological Bulletin, 130, 80-114. http://dx.doi.org/10.1037/0033-2909.130.1.80

Becker, J. C. (2012). The system-stabilizing role of identity management strategies: Social creativity can undermine collective action for social change. Journal of Personality and Social Psychology, 103, 647-662. http://dx.doi.org/10.1037/a0029240

Brewer, M. B. (1988). A dual process model of impression formation. In R. S. Wyer \& T. K. Srull (Eds.), Advances in social cognition (Vol. 1, pp. 1-36). Hillsdale, NJ: Lawrence Erlbaum Associates.

Byrne, B. (2011). Structural equation modeling with Mplus: Basic concepts, applications, and programming. London, UK: Routledge Academic.

Byrne, B. M., Shavelson, R. J., \& Muthén, B. (1989). Testing for the equivalence of factor covariance and mean structures: The issue of partial measurement invariance. Psychological Bulletin, 105, 456-466. http://dx.doi.org/10.1037/0033-2909.105.3.456

Cheung, G. W., \& Rensvold, R. B. (2002). Evaluating goodness-of-fit indexes for testing measurement invariance. Structural Equation Modeling, 9, 233-255. http://dx.doi.org/10.1207/S15328007SEM0902_5 
Correia, I., Alves, H., Sutton, R., Ramos, M., Gouveia-Pereira, M., \& Vala, J. (2012). When do people derogate or psychologically distance themselves from victims? Belief in a just world and ingroup identification. Personality and Individual Differences, 53, 747-752. http://dx.doi.org/10.1016/j.paid.2012.05.032

Cruwys, T., Platow, M. J., Angullia, S. A., Chang, J. M., Diler, S. E., Kirchner, J. L., ... Wadley, A. L. (2012). Modeling of food intake is moderated by salient psychological group membership. Appetite, 58, 754-757. http://dx.doi.org/10.1016/j.appet.2011.12.002

Danel, D. P., Fedurek, P., Coetzee, V., Stephen, I. D., Nowak, N., Stirrat, M., ...Saxton, T. K. (2012). A Cross-Cultural Comparison of Population-Specific Face Shape Preferences (Homo sapiens). Ethology, 118, 1173-1181. http://dx.doi.org/10.1111/eth.12022

Gaertner, L., \& Schopler, J. (1998). Perceived ingroup entitativity and intergroup bias: an interconnection of self and others. European Journal of Social Psychology, 28, 963-980. http://dx.doi.org/10.1002/(sici)1099-0992(1998110)28:6<963::aid-ejsp905>3.0.co;2-s

Gee, A., \& McGarty, C. (2013). Aspirations for a cooperative community and support for mental health advocacy: A shared orientation through opinion-based group membership. Journal of Applied Social Psychology, 43, E426-E441. http://dx.doi.org/10.1111/jasp.12021

Giamo, L. S., Schmitt, M. T., \& Outten, H. R. (2012). Perceived discrimination, group identification, and life satisfaction among multiracial people: A test of the rejectionidentification model. Cultural Diversity \& Ethnic Minority Psychology, 18, 319-328. http://dx.doi.org/10.1037/a0029729

Good, J. J., Moss-Racusin, C. A., \& Sanchez, D. T. (2012). When do we confront? Perceptions of costs and benefits predict confronting discrimination on behalf of the self and others. Psychology of Women Quarterly, 36, 210-226. http://dx.doi.org/10.1177/0361684312440958 
Hamilton, D. L., Sherman, S. J., \& Castelli, L. (2002). A group by any other name: The role of entitativity in group perception. In W. Stroebe \& M. Hewstone (Eds.), European review of social psychology (Vol. 12, pp. 139-166). New York, NY: Wiley.

Hartmann, T., \& Tanis, M. (2013). Examining the Hostile Media Effect as an Intergroup Phenomenon: The Role of Ingroup Identification and Status. Journal of Communication, 63, 535-555. http://dx.doi.org/10.1111/jcom.12031

Howard, M. C. (2014). An epidemiological assessment of online groups and a test of a typology: What are the (dis)similarities of the online group types? Computers in Human Behavior, 31, 123-133. http://dx.doi.org/10.1016/j.chb.2013.10.021

Howard, M. C., \& Magee, S. M. (2013). To boldly go where no group has gone before: An analysis of online group identity and validation of a measure. Computers in Human Behavior, 29, 2058-2071. http://dx.doi.org/10.1016/j.chb.2013.04.009

Hu, L. t., \& Bentler, P. M. (1999). Cutoff criteria for fit indexes in covariance structure analysis: Conventional criteria versus new alternatives. Structural Equation Modeling: A Multidisciplinary Journal, 6, 1-55. http://dx.doi.org/10.1080/10705519909540118

Kenny, D. A., \& Garcia, R. L. (2012). Using the actor-partner interdependence model to study the effects of group composition. Small Group Research, 43, 468-496. http://dx.doi.org/10.1177/1046496412441626

Koval, P., Laham, S. M., Haslam, N., Bastian, B., \& Whelan, J. A. (2012). Our Flaws Are More Human Than Yours: Ingroup Bias in Humanizing Negative Characteristics. Personality and Social Psychology Bulletin, 38, 283-295. http://dx.doi.org/10.1177/0146167211423777

Leach, C. W., Mosquera, P. M. R., Vliek, M. L. W., \& Hirt, E. (2010). Group Devaluation and Group Identification. Journal of Social Issues, 66, 535-552. http://dx.doi.org/10.1111/j.1540-4560.2010.01661.x 
Leach, C. W., van Zomeren, M., Zebel, S., Vliek, M. L. W., Pennekamp, S. F., Doosje, B., ... Spears, R. (2008). Group-level self-definition and self-investment: A hierarchical (multicomponent) model of in-group identification. Journal of Personality and Social Psychology, 95, 144-165. http://dx.doi.org/10.1037/0022-3514.95.1.144

Lickel, B., Hamilton, D. L., Wieczorkowska, G., Lewis, A., Sherman, S. J., \& Uhles, A. N. (2000). Varieties of groups and the perception of group entitativity. Journal of Personality and Social Psychology, 78, 223-246. http://dx.doi.org/10.1037//0022$\underline{3514.78 .2 .223}$

Philpot, C. R., \& Hornsey, M. J. (2011). Memory for intergroup apologies and its relationship with forgiveness. European Journal of Social Psychology, 41, 96-106. http://dx.doi.org/10.1002/ejsp.741

Phinney, J. S. (1992). The multigroup ethnic identity measure: A new scale for use with diverse groups. Journal of Adolescent Research, 7, 156-176. http://dx.doi.org/10.1177/074355489272003

Pickett, C. L., \& Perrott, D. A. (2004). Shall I compare thee? Perceived entitativity and ease of comparison. Journal of Experimental Social Psychology, 40, 283-289. http://dx.doi.org/10.1016/s0022-1031(03)00121-5

Riketta, M. (2005). Organizational identification: A meta-analysis. Journal of Vocational Behavior, 66, 358-384. http://dx.doi.org/10.1016/j.jvb.2004.05.005

Sani, F., Herrera, M., Wakefield, J. R. H., Boroch, O., \& Gulyas, C. (2012). Comparing social contact and group identification as predictors of mental health. British Journal of Social Psychology, 51, 781-790. http://dx.doi.org/10.1111/j.2044-8309.2012.02101.x

Schubert, T. W., \& Otten, S. (2002). Overlap of self, ingroup, and outgroup: Pictorial measures of self-categorization. Self and Identity, 1, 353-376. http://dx.doi.org/10.1080/152988602760328012 
Shepherd, L., Spears, R., \& Manstead, A. S. R. (2013). 'This will bring shame on our nation': The role of anticipated group-based emotions on collective action. Journal of Experimental Social Psychology, 49, 42-57. http://dx.doi.org/10.1016/j.jesp.2012.07.011

Smith, L. G. E., Amiot, C. E., Callan, V. J., Terry, D. J., \& Smith, J. R. (2012). Getting new staff to stay: The mediating role of organizational identification. British Journal of Management, 23, 45-64. http://dx.doi.org/10.1111/j.1467-8551.2010.00728.x

Stryker, S., \& Serpe, R. T. (1982) Commitment, identity salience, and role behavior: Theory and research example. In W. Ickes \& E. S. Knowles (Eds.), Personality, roles, and social behavior (pp. 199-218). New York, NY: Springer-Verlag.

Stürmer, S., Benbow, A. E. F., Siem, B., Barth, M., Bodansky, A. N., \& Lotz-Schmitt, K. (2013). Psychological foundations of xenophilia: The role of major personality traits in predicting favorable attitudes toward cross-cultural contact and exploration. Journal of Personality and Social Psychology, 105, 832-851. http://dx.doi.org/10.1037/a0033488

Swann, W. B., Gomez, A., Seyle, D. C., Morales, J. F., \& Huici, C. (2009). Identity Fusion: The Interplay of Personal and Social Identities in Extreme Group Behavior. Journal of Personality and Social Psychology, 96, 995-1011. http://dx.doi.org/10.1037/a0013668

Swann, W. B., Jetten, J., Gomez, A., Whitehouse, H., \& Bastian, B. (2012). When group membership gets personal: A theory of identity fusion. Psychological Review, 119, 441456. http://dx.doi.org/10.1037/a0028589

Tajfel, H. (1978). Social categorization, social identity, and social comparison. In H. Tajfel (Ed.), Differentiation between social groups. Studies in the social psychology of intergroup relations (pp. 61-76). London, UK: Academic Press.

Tajfel, H., \& Turner, J. C. (1986). The social identity theory of intergroup conflict. In S. Worchel \& W. G. Austin (Eds.), Psychology of intergroup relations (pp. 7-24). Chicago, IL: Nelson-Hall. 
Tatarko, A. N., \& Lebedeva, N. М. (2011). Методьь этнической и кросскультурной психологии [Methods of ethnic and cross-cultural psychology]. Moscow, Russia: NRU HSE, 2011.

Turner, J. C., Hogg, M. A., Oakes, P. J., Reicher, S. D., \& Wetherell, M. S. (1987). Rediscovering the social group. Oxford, UK: Blackwell.

van Veelen, R., Otten, S., \& Hansen, N. (2013). Social identification when an in-group identity is unclear: The role of self-anchoring and self-stereotyping. British Journal of Social Psychology, 52, 543-562. http://dx.doi.org/10.1111/j.2044-8309.2012.02110.x

Wang, J., Minervino, C., \& Cheryan, S. (2013). Generational differences in vulnerability to identity denial: The role of group identification. Group Processes \& Intergroup Relations, 16, 600-617. http://dx.doi.org/10.1177/1368430212461963 


\section{Appendix}

Russian version of items measuring in-group identification

1. Я чувствую свою связь с [ингруппа]

2. Я солидарен с [ингруппа]

3. Я ощущаю свою приверженность [ингруппа]

4. Я рад, что являюсь частью [ингруппа]

5. Я думаю, что [ингруппа] есть чем гордиться

6. Мне приятно быть частью [ингруппа]

7. Принадлежность к [ингруппа] делает меня счастливым

8. Я часто думаю о том, что я [представитель ингруппы]

9. Принадлежность к [ингруппа] накладывает отпечаток на мою личность

10. Принадлежность к [ингруппа] - важная часть моего представления о себе

11. У меня много общего со среднестатистическим [представитель ингруппы]

12. Я похож на среднестатистического [ингруппа]

13. У [представителей ингруппы] много общего между собой

14. Все [представители ингруппы] очень похожи друг на друга 